\title{
EFFECT OF THE ADDITION OF RICE HUSK IN TECHNOLOGICAL PROPERTIES OF MATERIALS FOR THE MANUFACTURE OF CERAMIC
}

\author{
J. Bautista-Ruiz ${ }^{1,2}$, J. Sánchez-Molina ${ }^{1,2, 凶}$, and J.V. Sánchez-Zúñiga ${ }^{1}$ \\ ${ }^{1}$ Universidad Francisco de Paula Santander, San José de Cúcuta - 540005, Colombia \\ ${ }^{2}$ Centro de Investigación en Materiales Cerámicos/Universidad Francisco de Paula Santander, \\ San José de Cúcuta - 540005, Colombia \\ ${ }^{\square}$ Corresponding Author: jorgesm@ufps.edu.co
}

\begin{abstract}
In this study, the rice husk discarded by the agro-industrial rice company in the department of Norte de Santander (Colombia) was used to replace clay material in the manufacture of tile-type ceramics. The materials were used to make test specimens with the presence of $5 \%, 10 \%, 15 \%$, and $20 \%$ (weight) of scale and with three different types of grain size $(1180 \mu \mathrm{m}, 180 \mu \mathrm{m}$, and $75 \mu \mathrm{m}$ mesh through). The specimens were molded using the extrusion technique. The shaped materials were subjected to different firing temperatures $\left(900{ }^{\circ} \mathrm{C}, 1000{ }^{\circ} \mathrm{C}, 1100{ }^{\circ} \mathrm{C}, 1150{ }^{\circ} \mathrm{C}\right.$, and 1200 ${ }^{\circ} \mathrm{C}$ ) to establish correlations between the microstructure/topography of the material and some of the technological properties of the ceramic such as the mechanical resistance to bending, resistance to deep abrasion, percentage of water absorption and linear drying/cooking shrinkage. The results show that proportions higher than $10 \%$ of rice husk do not obtain ceramics with ideal technological properties for use as pavement or coating. The best results were obtained when the husk was used at $5 \%$ and $180 \mu \mathrm{m}$ mesh through grain size. The X-ray diffraction analysis of the cooked samples shows significant changes in the proportion of phases formed (test tubes with and without substitution of clay material) as the temperature increases.
\end{abstract}

Keywords: Rice Husk, Circular Economy, Ceramics, Clay Material, Physical-ceramic Properties.

RASĀYAN J. Chem., Vol. 14, No.2, 2021

\section{INTRODUCTION}

The circular economy, the rule of the three Rs, and the carbon footprint have influenced the academic community to find improvements to many processes that allow the use of waste generated in other industrial processes to contribute to society's sustainable development. ${ }^{1-4}$

A new trend in the ceramic industry is the use of waste as a substitute for traditional raw materials and obtaining ceramics with technological properties for use in the construction industry..$^{5-7}$ Among the agroindustrial type, residues are the rice husk, the coffee cisco, the sugarcane bagasse, among others. ${ }^{8-10}$ The rice husk comprises an organic part and a high content of silica (between 15 and 20\%). ${ }^{11,12}$ These characteristics have allowed the development of studies that will enable determining the potential use of these residues as a substitute for clay materials to manufacture ceramic products for construction. ${ }^{13-18}$

A large amount of research associated with rice husk in ceramic materials is evident in the literature. ${ }^{19}$ However, further studies are necessary to understand the role this technological nutrient plays in a ceramic paste, especially in the field associated with floors and coatings. Questions such as: are there differences in the physical-ceramic properties according to the forming method? Will the grain size of the husk have any effect? How much do the physical-ceramic properties change with rice husk as the cooking temperature increases? Have attracted the attention of the authors.

The purpose of this research is to deepen the influence of the grain size of the rice husk on some of the physical-ceramic properties in tile-like products for the construction sector (non-enameled ceramic tile), taking into account for this analysis microstructural aspects and topographic. In this particular case, rice husk has been used, and the extrusion technique shapes the ceramic test specimens. 
RASĀYAN J. Chem.

Vol. 14 | No. 2 |712-718| April - June | 2021

\section{EXPERIMENTAL}

\section{Material and Methods}

The clay material for the study was taken in the municipality of El Zulia, Norte de Santander (Colombia). $\mathrm{CM}$ is a material with red clays of sedimentary type, which geologically are part of the "Guayabo Group," as described in the literature. ${ }^{20}$ The rice husk (RH) was supplied by the Arrocera Gélvez S.A.S, located in the same geographic region. Table-1 shows the codes for ceramic pastes made, taking into account the rice husk's proportion and grain size.

Table-1: Coding of Proposed Ceramic Pastes

\begin{tabular}{c|c|c|c|c}
\hline \multirow{2}{*}{ The Grain Size of Rice Husk } & \multicolumn{4}{|c}{ Rice Husk (\% Weight) } \\
\cline { 2 - 5 } & 5 & 10 & 15 & 20 \\
\hline$<$ Mesh $16(1180 \mu \mathrm{m})$ & CAa-5 & CAa-10 & CAa-15 & CAa-20 \\
\hline$<$ Mesh $80(180 \mu \mathrm{m})$ & CAb-5 & CAb-10 & CAb-15 & CAb-20 \\
\hline$<$ Mesh $200(75 \mu \mathrm{m})$ & CAc-5 & CAc-10 & CAc-15 & CAc-20 \\
\hline
\end{tabular}

From the raw materials mentioned above, various ceramic pastes were made. One of them is the traditional ceramic paste, in which approximately $80 \%$ of clay material is used. In comparison, others replace the participation of clay by rice husk in $5 \%$ ( $75 \%$ of CM), $10 \%$ (70\% of CM), $15 \%(65 \%$ of CM), and $20 \%$ $(60 \%$ of $\mathrm{CM})$, each one in its 3 -grain sizes. The ceramic paste is initially moistened up to $20 \%$ to guarantee the vacuum extrusion conditions. The specimens were shaped in a parallelepiped shape with $3.96 \mathrm{~cm}$ wide, $1 \mathrm{~cm}$ high, and $12 \mathrm{~cm}$ long. The equipment used was a New Wave series 101 laboratory extruder. Once formed, the specimens were dried in the environment $\left(25^{\circ} \mathrm{C}\right)$ for 24 hours and later artificially at $110^{\circ} \mathrm{C}$ in a Franco Gabbrielli laboratory stove. Technology for the same time or until constant mass. After removed the free water, took length measurements to know the variation produced before and after drying, with a digital caliper's help. ${ }^{21}$

They cooked the samples at different temperature peaks: $900{ }^{\circ} \mathrm{C}, 1000^{\circ} \mathrm{C}, 1100^{\circ} \mathrm{C}, 1150{ }^{\circ} \mathrm{C}$, and $1200{ }^{\circ} \mathrm{C}$, in an air atmosphere and a thermal gradient of $5^{\circ} \mathrm{C} /$ minute until reaching the highest temperature, which held for 120 minutes in a Gabbrielli 50019 brand oven with 220v power. As in drying, once cooked, the specimens were measured according to ASTM C326-03 to establish length changes. The procedure described in the Colombian Technical Standard NTC 4321-3 determined the degree of water absorption. With NTC 4321-4, the mechanical resistance to flexion offered by the ceramic product at scale was estimated. For the latter, a Gabbrielli brand press, model Flexi 1000-650, was used, which exerts a loading speed of 1 N/s. Finally, according to NTC 4321-6 in Gabbrielli CAP/3 equipment, the specimens were tested to establish their resistance to deep abrasion, a property related to the product's passability.

The ceramics obtained were characterized by an X-ray diffractometer model D8 ADVANCE with DaVinci Geometry $\left(\mathrm{CuK} \alpha_{1}\right.$ Radiation) and BRUKER brand step-by-step scan is carried out under conditions of 40 $\mathrm{kV}$, a step of $0.02035^{\circ}(2 \theta)$ and sampling time of $3 / 5 \mathrm{~s}$. The diffraction patterns of the International Center for Diffraction Data (ICDD) PDF-2 were used to identify the crystal structures according to the reflection planes exhibited by the samples. The Rietveld technique was used together with the X'pert HighScore Plus software from PANalytical.

Additionally, the test piece's surface showed the best physical-ceramic properties, and the reference material was analyzed morphologically using Scanning Electron Microscopy (SEM) at different temperatures. The equipment used was an EM30AX plus microscope from Coxem CO. LTD, operating at 20kV.

\section{RESULTS AND DISCUSSION}

The results of monitoring Drying Shrinkage (LDS), Firing Shrinkage (FS), Water Absorption Percentage (WAP), Mechanical Flexural Strength (FR), and Deep Abrasion Resistance (DAR) for the material of reference (MA) and the different modifications with rice husk (RH) are presented in Figs.-1 to 5.

From the results presented in Fig.-1, it can see that the use of RH as a substitute material significantly reduces shrinkage during the drying process. It is observed that the grain size and the proportion of rice husk influence the results. Notably, RH with larger grain sizes (RHa) induces a minor variation in drying 
RASĀYAN J. Chem.

Vol. 14 | No. 2 |712-718| April - June | 2021

shrinkage (LDS). On the other hand, using an ideal grain size increases the contraction, becoming more evident when the RH concentration is higher.

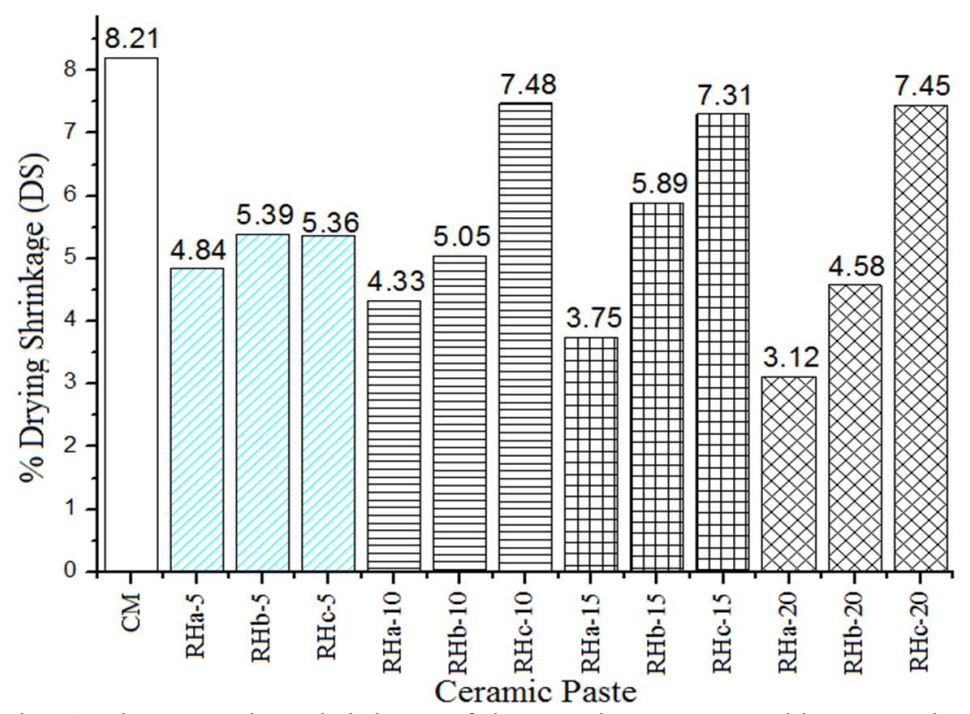

Fig.-1: Linear Drying Shrinkage of the Specimens Formed by Extrusion.

Figures-2 and 3 present the results of linear cooking contraction and the percentage of water absorption. From the information in Fig.-2, it is evident that CM's substitutions by rice husk in proportions more significant than $10 \%$ contribute to increasing the value of linear shrinkage in the firing. This fact makes dimensional control of ceramic products for construction such as coatings and pavements. It can be observed about RH's grain size, the apparent reduction of the FS by the use of finer particulate. This statement arises because the specimens prepared with the RHc-5 and RHc-10 pastes showed lower variations than the $\mathrm{CM}$ ceramic.

Concerning Fig.-3, it is observed that the higher the RH concentration, the porosity of the ceramic material increases. This behavior is associated with eliminating the organic phase present in the RH material in the calcination process. This characteristic of the material can be corroborated in the SEM micrographs of Fig.6. Likewise, a more significant substitution of CM (especially kaolinite and muscovite) could reduce the vitreous phase formation, affecting the densification process. ${ }^{20}$ The paste with the company of rice husk that allows obtaining the lowest percentage of water absorption is that with only $5 \%$ substitution and intermediate grain size, this is CAb-5 (180 $\mu \mathrm{m}$ through the mesh)

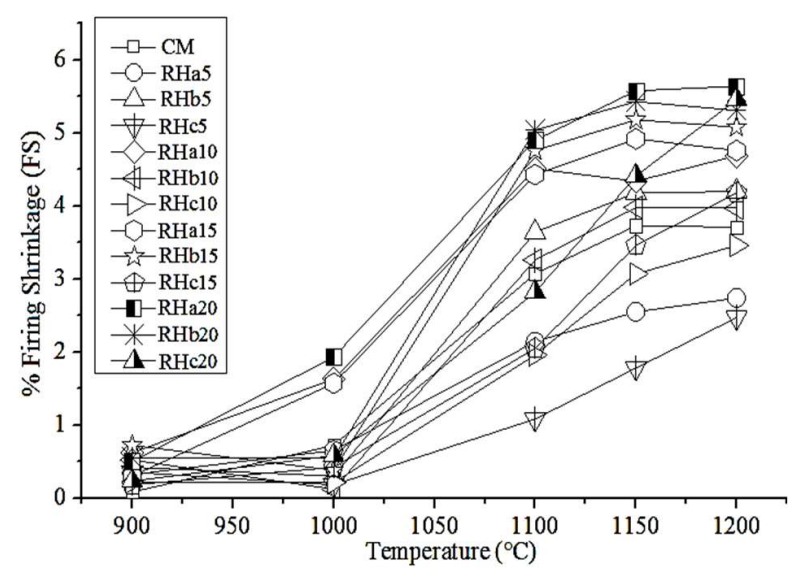

Fig.-2: Linear Firing Contraction of the Specimens

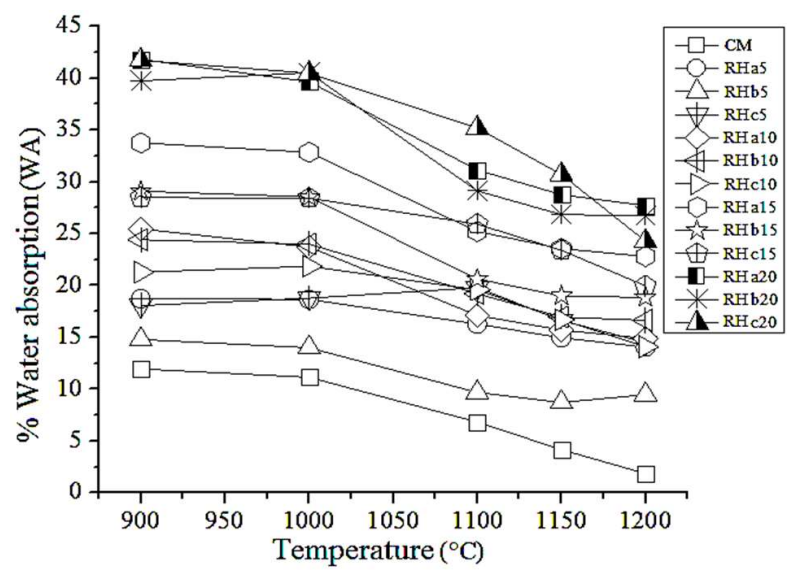

Fig.-3: Percentage of Water Absorption of Ceramic Specimens at Different Firing Temperatures. 
RASĀYAN J. Chem.

Vol. 14 | No. 2 |712-718| April - June | 2021

Figure-4 shows an inversely proportional relationship between the amount of added rice husk and the RF value. No ceramics made with RH improved the specimens values made with only CM for the studied temperature range. No significant differences are observed in Fig.-4 to establish which type of granulometry is most suitable for enhancing FR. The best results were obtained with the RHb-5 and RHa-10 pastes. The porosity and black heart is possible, caused by $\mathrm{Fe} 3+$ reduction $\mathrm{Fe}^{2+}$ and $\mathrm{Fe}^{0}$ in the combustion process of the organic matter of $\mathrm{RH}^{21}$

The results of mechanical resistance to deep abrasion (DAR) of the fired samples are presented in Fig.-5. The use of RH brings important changes in the toughness of the ceramics obtained. The results do not seem to show a clear trend with the substitution of CM for RH. For example, the results for RHa-20 and RHc20 are contradictory regarding the behavior observed for MA ceramics. On the other hand, RH's grain size significantly influences this technological property, explaining the differences obtained for RHa- 20 and RHc20.

In the literature review, no research with experimental designs similar. The only variable with comparison criteria has been the percentage of water absorption, which showed that the results are better than those reported in the literature. ${ }^{22,}{ }^{23}$ However, it is essential to highlight that these works do not use cooking temperatures higher than $1000{ }^{\circ} \mathrm{C}$.

From the values of the technological properties, it is proposed that ceramics with concentrations higher than $10 \%$, in most cases, bring more negative than positive effects compared to CM. Regarding grain size, the results do not show a clear trend for decision-making either. The mechanical resistance to flexion (FR) is one of the most critical variables when establishing a ceramic for floor or pavement. The breaking load of the different ceramic materials obtained was compared to specify which ones exceed the minimum value found in the literature for construction applications in floors and coatings ( $400 \mathrm{~N}$ in coatings and $900 \mathrm{~N}$ for pedestrian pavements). ${ }^{24}$ The analysis carried out showed that only RHa-10 and RHb-5 pastes could exceed the minimum breaking load by $900^{\circ} \mathrm{C}$. Also, they are the only ones that can have application as a pedestrian pavement, as long as the cooking temperature exceeds $1100^{\circ} \mathrm{C}$ according to the analysis carried out. In the case of ceramics made with only $\mathrm{CM}$, at $1000^{\circ} \mathrm{C}$, it is already possible to obtain the $900 \mathrm{~N}$ required for use as a pedestrian pavement, reducing the economic interest of using $\mathrm{RH}$ for manufacturing ceramics for the construction sector.

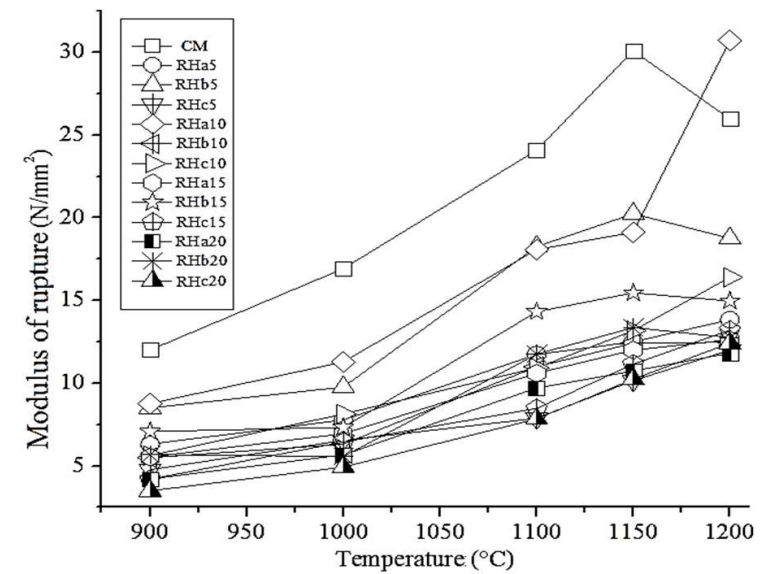

Fig.-4: Changes in Mechanical Flexural Resistance (FR) with increasing Temperature

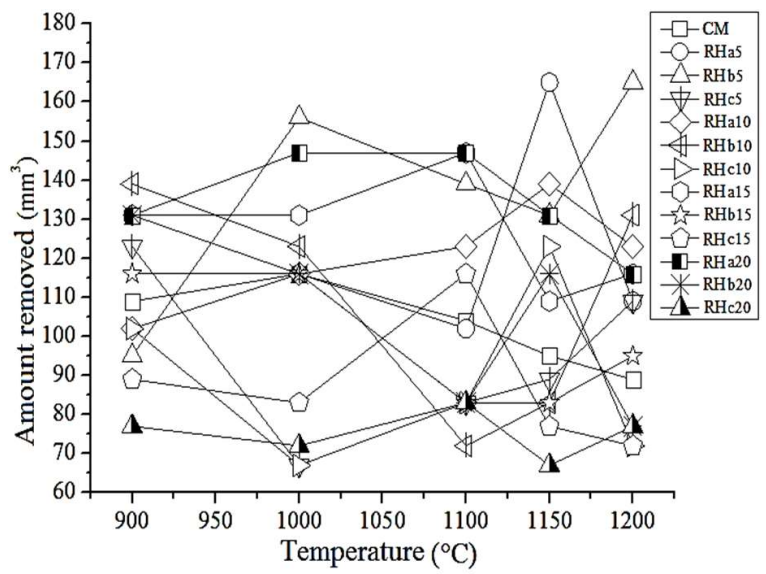

Fig.-5: Changes in Deep Abrasion Resistance (DAR) with increasing Temperature.

The clay material's microstructural behavior and the mixture with the best physical-ceramic properties were evaluated when subjected to high temperatures. In this analysis, we worked with the RHb-5 paste, which reached the highest breaking load and the lowest water absorption in the temperature range evaluated for RHa- 10.

The DRX and MEB results for ceramics made with the CM and RHb-5 pastes and at three different firing temperatures are presented in Table-2 and Fig.-6. 
RASĀYAN J. Chem.

Vol. 14 | No. 2 |712-718| April - June | 2021

Table-2: Microstructural Composition of CM and RHb-5 Ceramics at Different Firing Temperatures (wt\%)

\begin{tabular}{c|c|c|c|c|c|c}
\hline \multirow{2}{*}{ Phase } & \multicolumn{3}{|c|}{$\mathrm{CM}$} & \multicolumn{3}{c}{$\mathrm{RHb} 5$} \\
\cline { 2 - 7 } & $1000{ }^{\circ} \mathrm{C}$ & $1100{ }^{\circ} \mathrm{C}$ & $1200{ }^{\circ} \mathrm{C}$ & $1000{ }^{\circ} \mathrm{C}$ & $1100{ }^{\circ} \mathrm{C}$ & $1200{ }^{\circ} \mathrm{C}$ \\
\hline Quartz & 60.2 & 42.3 & 34.6 & 49.1 & 47.2 & 47.6 \\
\hline Hematite & 3.4 & 2.7 & 2.9 & 3.3 & 3.3 & 3.3 \\
\hline Rutile & 1.0 & 0.8 & 0.8 & 0.3 & 0.1 & --- \\
\hline Microcline & 1.0 & 0.0 & 0.0 & 1.4 & 0.7 & 0.2 \\
\hline Mullite & 2.5 & 22.6 & 25.4 & --- & 15.1 & 19.9 \\
\hline $\begin{array}{c}\text { Cristobalite low } \\
\text { (760938) }\end{array}$ & 0.5 & 7.1 & 4.5 & --- & 0.5 & 7.4 \\
\hline $\begin{array}{c}\text { Cristobalite low } \\
\text { (760941) }\end{array}$ & 0.0 & 0.7 & 18.4 & --- & --- & --- \\
\hline Muscovite & 0.0 & 0.0 & 0.0 & 5.5 & --- & --- \\
\hline Pseudobrookite & --- & --- & --- & --- & --- & 0.7 \\
\hline Crystalline & 68.6 & 76.2 & 86.6 & 59.7 & 66.8 & 79.1 \\
\hline Amorphous & 31.4 & 23.8 & 13.4 & 40.3 & 33.2 & 20.9 \\
\hline
\end{tabular}

From the information presented in Table-2, differences in the reaction mechanism at high temperatures can be observed between the ceramic pastes $\mathrm{CM}$ and $\mathrm{RHb}-5$. For example, when analyzing the amorphous proportion changes, a reduction of $57 \%$ was evident for $\mathrm{CM}$ and $48 \%$ for RHb-5. Also, the transformation speed is more pronounced in MA, taking the temperature of $1100^{\circ} \mathrm{C}$ as a comparison point.
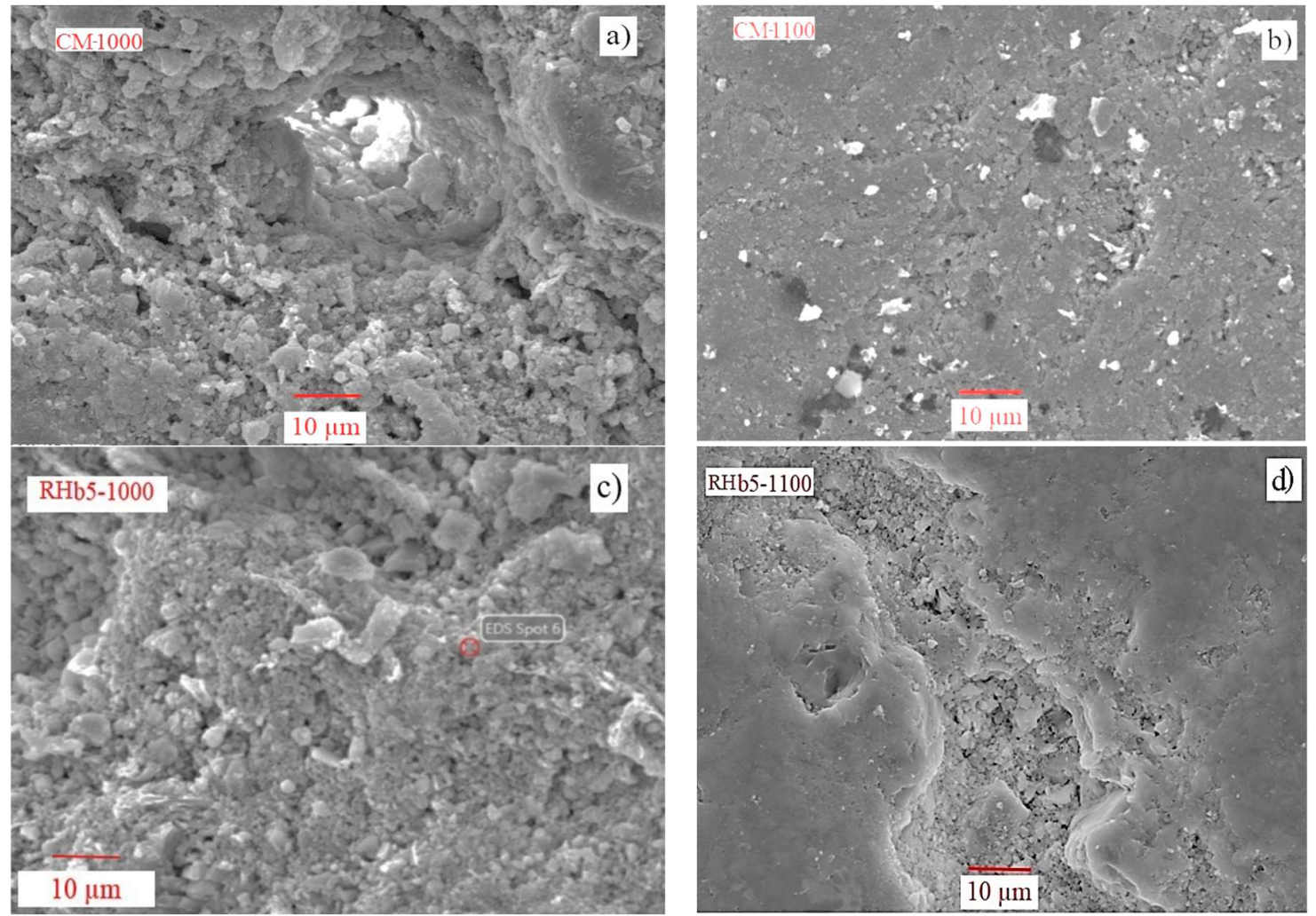

Fig.-6: Micrographs of CM and RHb-5 Ceramics at Different Firing Temperatures (2000X).

On the other hand, when raising the cooking temperature, significant differences are evident in the mass proportion of the quartz phase. While in the CM ceramic, the balance is reduced by approximately $42 \%$, and in RHb-5, it only changed by $3 \%$. This result allows us to affirm that even at low levels of substitution of $\mathrm{CM}$ for $\mathrm{RH}$, essential changes can be generated in the ceramic microstructure as the temperature burns. 
RASĀYAN J. Chem.

Vol. 14 | No. 2 |712-718| April - June | 2021

These changes may have a necessary influence on the technological properties evaluated. For example, it could be hypothesized that a more significant presence of quartz in RHb-5 concerning $\mathrm{CM}$ affects the ceramic's mechanical resistance because it does not favor sintering as does a silica vitreous formed in CM. The results of Table- 2 also allow inferring the behaviors in the quartz phase. When observing the data associated with the cristobalite phase, differences are also seen between the data found for both types of ceramics. According to the results, it could be thought that there is an inversely proportional relationship between the percentages of cristobalite and quartz for the CM material, a statement adjusted to that reported by other researchers. ${ }^{25}$ Although visible in $\mathrm{RHb}-5$, this behavior is not as pronounced, possibly due to the effect of the addition of rice husk.

In the case of the mullite phase (see Table-2), it is evident that in CM a higher concentration of this phase always appears at all the temperatures evaluated. In the consulted literature, mullite in adequate proportions in the ceramic allows improving its mechanical resistance ${ }^{26}$. This statement could explain the RF results in the present investigation.

Results by scanning electron microscopy, in Fig.-6, it can be seen that the topography of the ceramic is affected by the firing temperature and by the presence of the rice husk. At the firing temperature of 1000 ${ }^{\circ} \mathrm{C}$, the ceramics CM (Fig.-6a) and RHb-5 (Fig.-6c) do not show significant differences at the topographic level. However, at higher temperatures, important changes are evident in each one. In the CM ceramic fired at $1100{ }^{\circ} \mathrm{C}$ (Fig.-6b), the grains greater sintering is notable. A much more homogeneous surface is observed, with pores of size not exceeding 7 micrometers. Concerning the RHb-5 material (Figure 6d), cooked at $1100{ }^{\circ} \mathrm{C}$, although an increase in the grains sintering and a higher degree of vitrification is evident, the surface is not homogeneous. It is common to find large pores and the presence of crater-like areas that (in the image $25 \mu \mathrm{m}$ wide and more than $100 \mu \mathrm{m}$ long) are most likely generated by the total decomposition of organic matter present in the scale of rice $(180 \mu \mathrm{m}$ mesh through) and by the reaction of the residual inorganic phase at high temperatures. These topographic irregularities explain the high porosity and low mechanical resistance of ceramics made with rice husk.

\section{CONCLUSION}

In this research, it was evidenced that the substitution of clay material for rice husk for the manufacture of ceramics (not enameled) in floors and pavements does not allow obtaining products with better technological properties compared to the ceramic reference material $(\mathrm{CM})$ in any of the temperatures at which it was evaluated. In substitutions greater than $10 \%$, ceramics do not achieve sufficient mechanical resistance to bending to be used at least as a coating.

Regarding the impact that the grain size of the technological nutrient can have, it was evident that for some of the technical variables analyzed, if significant differences are found, the most relevant are the linear drying shrinkage (LDS) and the mechanical resistance to abrasion deep (DAR).

The RHa-10 and RHb-5 pastes are the ones that have the most possibility to be used when making ceramic tiles for flooring or paving. However, these ceramics' technological properties require higher firing temperatures than ceramics with only clay material (MA).

Finally, it showed that rice husks in the ceramic paste could significantly modify how solid-state reactions occur at high temperatures. The substitution of only $5 \%$ of CM by $180 \mu \mathrm{m}$ mesh through RH significantly changed the proportion of quartz, cristobalite, mullite, and the amorphous part present in the analyzed ceramics.

\section{ACKNOWLEDGMENT}

The authors thank the Ceramic Materials Research Center (CIMAC) of the Francisco de Paula Santander University for the technical support given and the work team of the University of Jaén.

\section{REFERENCES}

1. M.I. Almeida, A.C. Dias, M. Demertzi, and L. Arroja, Journal of Cleaner Production, 131, 583 (2016), DOI:10.1016/j.jclepro.2016.04.131

2. S. Prakash Chandar, K. Gunasekaran, K. Prasanth, and G. Senthil-Kumar. Rasayan Journal of Chemistry, 11(2), 702 (2018), DOI:10.31788/RJC.2018.1123003 
RASĀYAN J. Chem.

Vol. 14 | No. 2 |712-718| April - June | 2021

3. M. Vidya Vijay, J.S. Sudarsan, and S. Nithiyanantham, Rasayan Journal of Chemistry, 10(3), 1056(2017), DOI:10.7324/RJC.2017.1031738

4. J. Sharma, and B. Janveja, Rasayan Journal of Chemistry, 1(4), 936(2008).

5. L. Zhang, Construction and Building Materials, 47, 643(2013), DOI:10.1016/j.conbuildmat.2013.05.043

6. N.V. Boltakova, G.R. Faseeva, R.R. Kabirov, R.M. Nafikov, and Y.A. Zakharov, Waste Management, 60, 230(2017), DOI:10.1016/j.wasman.2016.11.008

7. D. Eliche, C. Martínez, M.L. Martínez, M.T. Cotes, L. Pérez, N. Cruz, and F.A. Corpas, Applied Clay Science, 52, 270(2011), DOI:10.1016/j.clay.2011.03.003

8. J Sánches-Molina, D.C. Alvarez-Rozo, J.F. Gelves-Díaz. Revista Respuestas, 23(1), 27(2018), DOI: $10.22463 / 0122820 X .1326$

9. A. Souza, S.R. Teixeira, G.T. A. Santos, F.B. Costa, and E. Longo, Journal of Environmental Management, 92(10), 277(2011), DOI:10.1016/j.jenvman.2011.06.020

10. E.G. García, and L. Lizárraga, Revista Académica de la Facultad de Ingeniería Universidad Autónoma de Yucatán, 19(2), 91(2015).

11. D. Chen, A. Gao, Z. Ma, D. Fei, Y. Chang, and C. Shen, Bioresource Technology, 253, 148(2018), DOI:10.1016/j.biortech.2018.01.009

12. P.W. Olupot, A. Candia, E. Menya, and R. Walozi, Chemical Engineering Research and Design, 107, 63(2016), DOI:10.1016/j.cherd.2015.11.010

13. A. Guzmán, J. Torres, M. Cedeño, S. Delvasto, V. Amigó, and E. Sánchez, Boletín de la Sociedad Española de Cerámica y Vidrio, 52(6), 283(2013), DOI:10.3989/cyv.352013

14. G. Görhan, and O. Şimşek, Construction and Building Materials, 40, 390(2013), DOI: $10.1016 /$ j.conbuildmat.2012.09.110

15. S. Janbuala, and T. Wasanapiarnpong, Key Engineering Materials, 659, 74(2015), DOI:10.4028/www.scientific.net/kem.659.74

16. K.Y. Chiang, P.H. Chou, C.R. Hua, K.L. Chien, and C. Cheeseman, Journal of Hazardous Materials, 171, 76(2009), DOI:10.1016/j.jhazmat.2009.05.144

17. G. Peña-Rodríguez, J. Sánchez-Molina, and R. Monroy. Revista Colombiana de Física, 40(2), 285(2008).

18. G.S. De Silva, and M.L.C. Surangi, Construction and Building Materials, 154, 251(2017), DOI:10.1016/j.conbuildmat.2017.07.169

19. A.O. Florez-Vargas, J. Sánchez-Molina, D.S. Blanco-Meneses. Revista Escuela de Ingeniería de Antioquia, 15(30), 133(2018), DOI:10.24050/reia.v15i30.1219

20. J. Linares, F. Huertas, and J. Capel. Cuadernos de Prehistoria y Arqueología de la Universidad de Granada, 8, 479(1983).

21. M. Fernández, Manual sobre fabricación de baldosas, tejas y ladrillos, Igualada, España, p.280,360(2000).

22. J. García-Ten, G. Silva, V. Cantavella, and M. Lorente, Conarquitectura, 16, 65(2005).

23. A.H. De Aza, P. Pena, A. Caballero, and S. Aza, Boletín de la Sociedad Española de Cerámica y Vidrio, 50(6), 279(2011), DOI:10.3989/cyv.372011

24. C. Aksel, Ceramics International, 29(2), 183(2003), DOI:10.1016/S0272-8842(02)00103-7

25. H Schneider, J. Schreuer, and B. Hildmann, Journal of the European Ceramic Society, 28(2), 329(2008), DOI: 10.1016/j.jeurceramsoc.2007.03.017

26. C.L. Hwang, and T.P. Huynh, Construction and Building Materials, 93, 335(2015), DOI:10.1016/j.conbuildmat.2015.04.061

[RJC- 5900/2020] 